\title{
Effect of mammography screening on surgical treatment for breast cancer in Norway: comparative analysis of cancer registry data
}

\author{
Pål Suhrke PhD candidate ${ }^{1}$, Jan Mæhlen professor ${ }^{1}$, Ellen Schlichting consultant breast surgeon ${ }^{2}$, \\ Karsten Juhl Jørgensen researcher ${ }^{3}$, Peter C Gøtzsche professor ${ }^{3}$, Per-Henrik Zahl senior \\ statistician $^{4}$
}

${ }^{1}$ Department of Pathology, Oslo University Hospital, N-0407 Oslo, Norway; ${ }^{2}$ Department of Breast and Endocrine Surgery, Oslo University Hospital, Norway; ${ }^{3}$ The Nordic Cochrane Centre, Rigshospitalet, Copenhagen, Denmark; ${ }^{4}$ Norwegian Institute of Public Health, Oslo, Norway

\begin{abstract}
Objective To determine the effect of mammography screening on surgical treatment for breast cancer.

Design Comparative analysis of data from Norwegian cancer registry.

Setting Mammography screening, Norway (screening of women aged 50-69 was introduced sequentially from 1996 to 2004).
\end{abstract}

Participants 35408 women aged 40-79 with invasive breast cancer or ductal carcinoma in situ treated surgically from 1993 to 2008.

Main outcome measures Rates of breast surgery (mastectomy plus breast conserving treatment) and rates of mastectomy for three age groups of women: 40-49, 50-69, and 70-79. Changes in rates from pre-screening period (1993-5) to introduction of screening phase (1996-2004) and then to screening period (2005-8) are presented as hazard ratios in invited and non-invited women.

Results The annual rate for breast surgery from the pre-screening period (1993-5) to screening period (2005-8) in Norway increased by $70 \%$ (hazard ratio $1.70,95 \%$ confidence interval 1.62 to 1.78 ), from 180 to 305 per 100000 women in the invited age group (50-69 years). In the younger, non-invited age group (40-49 years), however, the increase was only $8 \%(1.08,1.00$ to 1.16$)$, from 133 to 144 per 100000 women per year, whereas in the older, non-invited age group (70-79 years) the rate decreased by $8 \%(0.92,0.86$ to 1.00$)$, from 227 to 214 per 100000 women per year. The rates for mastectomy decreased similarly from the pre-screening period to screening period in invited and non-invited women. From the pre-screening period to the introduction phase of screening (1996-2004), however, the annual mastectomy rate in women aged 50-69 invited to screening increased by $9 \%$ (1.09, 1.03 to 1.14 ), from 156 to 167 per 100000 women, and in the younger non-invited women declined by $17 \%(0.83,0.78$ to 0.90$)$, from 109 to 91 per 100 000 women. In consequence, the mastectomy rate was $31 \%(1.31,1.20$ to 1.43 ) higher in the invited than in the non-invited younger age group.
Conclusions Mammography screening in Norway was associated with a noticeable increase in rates for breast cancer surgery in women aged 50-69 (the age group invited to screening) and also an increase in mastectomy rates. Although over-diagnosis is likely to have caused the initial increase in mastectomy rates and the overall increase in surgery rates in the age group screened, the more recent decline in mastectomy rates has affected all age groups and is likely to have resulted from changes in surgical policy.

\section{Introduction}

The objective of mammography screening is to improve the timing of breast cancer diagnosis, thereby reducing the number of associated deaths. A potential additional benefit often stated in invitations to screening and on websites supported by governmental screening institutions is that screening reduces the need for mastectomies and increases the potential for breast conserving treatment. ${ }^{1-3}$ In contrast, a Cochrane review of randomised trials on mammography reported a $31 \%$ increase in breast surgery (mastectomy plus breast conserving treatment) and $20 \%$ more mastectomies in women exposed to screening than in the control group. ${ }^{4}$

In the Norwegian breast cancer screening programme, women aged 50-69 are invited to biennial screening. The programme started in 1996 in the four counties of Akershus, Oslo, Rogaland, and Hordaland and included $40 \%$ of the Norwegian population. From 1999 to 2004 the remaining 15 counties were successively included. $^{5}$

We used Norwegian population based data for the period 1993 to 2008 to assess how the stepwise introduction of mammography screening has affected surgical treatment for breast cancer - that is, the number of women undergoing mastectomy or breast surgery (mastectomy or breast conserving treatment) for invasive breast cancer or ductal carcinoma in situ. 
We also determined how surgical treatment by disease stage at diagnosis has changed during the period.

\section{Methods}

From the Norwegian cancer registry we obtained aggregate data on incidence and surgical treatment of women aged 40-79 with ductal carcinoma in situ or invasive breast cancer. The data were stratified by stage and included the period 1993-2008. The cancer registry collects information on stage of disease at the time of diagnosis; stage 0 (ductal carcinoma in situ), stage I (invasive breast cancers of diameter $\leq 2.0 \mathrm{~cm}$ and no lymph node involvement or distant metastasis), stage II (invasive breast cancers of diameter $\leq 5.0 \mathrm{~cm}$ and 1-3 positive lymph nodes but no distant metastasis, or invasive breast cancers of diameter $>2.0 \mathrm{~cm}$ with no positive lymph nodes or distant metastasis), and stage III and IV (tumours of diameter $>5 \mathrm{~cm}$ and $1-3$ positive lymph nodes, any tumour with direct extension to chest wall or skin, any tumour with $>3$ positive lymph nodes, or any tumour with distant metastasis).

Based on clinical notifications and pathology reports the cancer registry classifies each patient (identified by a unique personal identification number) to have undergone either breast conserving treatment or mastectomy or neither. If breast conserving treatment is followed by mastectomy within four months, the case is coded as a mastectomy. We requested data on the treatment of primary cases - that is, the first episode of breast cancer for each woman. Cases of invasive cancer are counted whether or not the women have had ductal carcinoma in situ previously. Cases of ductal carcinoma in situ are counted only when the lesions have no invasive component, the women have not had invasive breast cancer previously, and the ductal carcinoma in situ is not followed by invasive breast cancer within four months.

\section{Statistical analysis}

We calculated age specific incidence rates, rates of breast surgery (breast conserving treatment plus mastectomy), and rates of mastectomy for invasive breast cancer and ductal carcinoma in situ grouped together for three age groups of women: 40-49, 50-69, and 70-79 years. Depending on the start of mammography screening, we stratified women aged 50-69 into two geographical subgroups (those from the counties of Akershus, Oslo, Rogaland, and Hordaland and those from the remaining 15 Norwegian counties) and calculated age specific mastectomy rates. To determine how the introduction of screening affected breast cancer surgery by stage, we calculated age specific mastectomy and breast surgery rates for stages 0 , I, II, and III/IV for women aged 50-69 years.

Based on the national availability of mammography screening, we divided the study period into pre-screening (1993-5), introduction of screening phase (1996-2004), and screening (2005-8). To compare changes in use of breast cancer surgery between periods with and without screening, we estimated changes in mastectomy and breast surgery rates in the three age groups from pre-screening to the introduction of screening phase and from pre-screening to screening. We used a Poisson regression model adjusting for age only. Changes in rates of surgery over time are presented as hazard ratios.

To determine changes in use of breast cancer surgery between screened and non-screened age groups, we used a Poisson model to compare the changes in mastectomy and breast surgery rates in women aged 50-69 versus women aged 40-49, adjusting for changes in age distribution and for an underlying linear trend.
Finally, we divided the data into two geographical subgroups, taking advantage of regional variations in the start of screening in Akershus, Oslo, Rogaland, and Hordaland counties and the remaining 15 counties. We compared mastectomy rates between women aged 50-69 and 40-49 in two periods; pre-screening (1993-5 in Akershus, Oslo, Rogaland, and Hordaland and 1993-8 in the other counties) and introduction of screening (1996-7 in Akershus, Oslo, Rogaland, and Hordaland and 1999-2004 in the other counties). In this analysis we used a Poisson model, adjusting for changes in age distribution and an underlying linear trend.

\section{Results}

In 2008 the Norwegian population included one million women aged 40-79. In the study period from 1993-2007 the cancer registry recorded 32200 cases of invasive breast cancer and 3208 cases of ductal carcinoma in situ in this age group. Data on surgical treatment were available for $94 \%$ of the invasive cancer cases and $98 \%$ of the ductal carcinoma in situ cases (table $1 \Downarrow$ ). Figure $1 \Downarrow$ presents the age specific incidence rates and rates of breast surgery and mastectomy for ductal carcinoma in situ and invasive breast cancer for the age groups 40-49, 50-69, and 70-79 combined. From 1996 to 2002 mastectomy rates decreased gradually in the 40-49 and 70-79 age groups but temporarily increased in the 50-69 age group. The increase was evident only in Akershus, Oslo, Rogaland, and Hordaland where prevalence screening was carried out in 1996-7 (fig $2 \Downarrow$ ). In the remaining counties where screening started later, mastectomy rates were stable from 1996-2002 (fig 2). From 2002-3 mastectomy rates declined in all counties.

Figure $3 \Downarrow$ shows the national rates for surgery stratified by stage of disease for women aged 50-69. Rates of breast surgery for stages 0 , I, and II all increased during the study period.

Mastectomy rates for stage I noticeably increased temporarily in the first three years when screening was introduced, and decreased after 2002. The mastectomy rates for stage 0 and stage II increased from 1996 but decreased from about 2003. Rates of mastectomies and breast surgery for stage III and IV tumours did not change noticeably.

Table $2 \Downarrow$ shows the annual rates of mastectomy and breast surgery for all stages of invasive cancer and for ductal carcinoma in situ in the three periods. The estimated hazard ratios comparing the pre-screening period with the screening introduction phase and the pre-screening period with screening period are also presented. During the screening introduction phase, mastectomy rates increased by $9 \%$ in the 50-69 age group but decreased by $17 \%$ in the $40-49$ age group and by $13 \%$ in the 70-79 age group. Using Poisson regression to compare the 1.09 relative change (invited women aged 50-69) with the expected 0.83 relative change (assuming a similar reduction between age groups 50-69 and 40-49) the relative risk of mastectomy in the 50-69 age group increases by $31 \%$ (hazard ratio $1.31,95 \%$ confidence interval 1.20 to 1.43 ).

From the pre-screening period to screening period the mastectomy rates decreased by $30 \%$ in the 50-69 age group, $35 \%$ in the $40-49$ age group, and $41 \%$ in the $70-79$ age group (table 2). Using a Poisson model the decrease in mastectomy rates did not differ significantly between the 50-69 and 40-49 age groups $(1.08,0.97$ to 1.21$)$. The total number of breast operations from the pre-screening to screening period increased by $70 \%$ in the 50-69 age group compared with $8 \%$ in the $40-49$ age group and decreased by $8 \%$ in the $70-79$ age group.

In contrast with Akershus, Oslo, Rogaland, and Hordaland, the mastectomy rate in the remaining counties did not increase in 
the screening introduction phase (fig 2). Women aged 50-69 were stratified in Akershus, Oslo, Rogaland, and Hordaland and the remaining counties and the hazard ratio for mastectomy compared between the pre-screening period and the screening introduction phase. During the screening introduction phase in Akershus, Oslo, Rogaland, and Hordaland (1996-7) mastectomy rates increased by $48 \%(1.48,1.23$ to 1.78$)$ in the $50-69$ age group relative to the rates in the 40-49 age group. In the remaining counties, screening was introduced later and more gradually. During the introduction of screening in these counties (1999-2004) mastectomy rates increased by $21 \%(1.21,1.09$ to 1.34 ) in the 50-69 age group relative to the rates in the $40-49$ age group.

\section{Discussion}

A potential benefit of mammography screening — a reduction in mastectomy rates and an increase the use of less invasive surgery-was not corroborated by our results, which show that mastectomy rates in Norway have declined similarly in invited and non-invited age groups from the pre-screening period (1993-5) to the more recent screening period (2005-8). During the introduction of screening, mastectomy rates in invited women aged 50-69 increased by $9 \%$. In contrast, during the same period the rates in non-invited women decreased by $17 \%$ in the $40-49$ age group and by $13 \%$ in the $70-79$ age group. This corresponds to a $31 \%$ increase in the relative risk of mastectomy in women invited to screening compared with the non-invited younger age group. Mastectomy rates noticeably increased in Akershus, Oslo, Rogaland, and Hordaland counties when screening started in 1996. Since the detection rate is higher during prevalence screening than in the subsequent screening rounds, more mastectomies would be expected in the prevalence screening round. In the remaining 15 Norwegian counties where screening was introduced later and more gradually in 1999-2004, the absolute number of mastectomies did not increase during the screening introduction phase; although in relative terms, the increase was $21 \%$ compared with the younger non-invited age group. The more modest change in mastectomy rates in the 15 counties in the screening introduction phase (smaller prevalence peak than in Akershus, Oslo, Rogaland, and Hordaland) can be explained by the more gradual introduction of the screening programme and the non-organised private screening activity before the screening programme started. In addition, during the observation period changes in surgical practice in Norway have reduced mastectomy rates in all age groups. As part of the mammography screening programme, specialist breast clinics with a focus on multidisciplinary teamwork between

radiologists, pathologists, and surgeons were established. As a consequence, the numbers of Norwegian hospitals carrying out breast cancer surgery have declined, from around 60 to $20 .^{6} \mathrm{It}$ is likely that this has influenced the treatment of non-screened age groups as a spin-off effect.

The mastectomy rates for stages 0 , I, and II increased in women aged 50-69 in the first years of the screening introduction phase. Rates decreased for all stages except III and IV from 2002-3, reflecting that changes in surgical practice affect both lymph node positive and negative invasive cancers with a diameter less than $5 \mathrm{~cm}$, as well as ductal carcinoma in situ. Rates of breast surgery have increased especially for stages 0 and I, but also for stage II.

The risk of surgery for invasive breast cancer or ductal carcinoma in situ increased by $70 \%$ in the 50-69 age group in the screening period compared with pre-screening period. In contrast, the risk increased by $8 \%$ in non-invited women in the
40-49 age group. The introduction of the Norwegian mammography screening programme was associated with a more than $50 \%$ increase in the incidence of invasive breast cancer in women aged 50-69. ${ }^{7}$ In addition many cases of ductal carcinoma in situ are detected by screening, and ductal carcinoma in situ now constitutes $13 \%$ of breast cancer diagnoses in Norway in the screened age group. A recent systematic review of five screening programmes estimated that screening is associated with a $52 \%$ over-diagnosis of breast cancer, including cases of ductal carcinoma in situ, which would not have been identified clinically in the women's remaining lifetimes. ${ }^{8}$

\section{Strengths and limitations of the study}

We used population based data from the Norwegian cancer registry, which contains virtually all cancers diagnosed in Norway, with only $0.5 \%$ of the cases lacking information on stage. ${ }^{9}$ The information on type of surgical treatment is also nearly complete, with only $5 \%$ of cases lacking a surgery code, either because of missing data or because the patient did not have surgery.

The rates of attendance in the Norwegian mammography screening programme are high and stable; $75-77 \%$ in $2002-6 .{ }^{5}$ In Norway the rates for ductal carcinoma in situ increased from 9 to 40 per 100000 women aged 50-69 from 1993 to 2008. In contrast the rates for ductal carcinoma in situ for women aged 40-49 and 70-79 have been essentially constant, indicating little screening activity outside the invited age group.

This study also has limitations. In addition to the stage and size of tumours, surgical treatment is influenced by several other patient, surgeon, and hospital factors. ${ }^{10}$ Since we used aggregated data, our options to adjust for factors other than the introduction of screening were limited. Geographical differences may have influenced the type of surgery chosen because of variation in surgical tradition and skills and because of the long travelling distances to radiation therapy units from some parts of Norway. By using the age group 40-49 as a control group, we limited potential bias from geographical differences because screen and non-screen detected cancers from an area are treated at the same breast clinics, and women aged 40-49 are generally expected to be offered the same treatment as women aged 50-69. Some cancers that currently are detected by screening in women aged 50-69 would in the absence of screening have been diagnosed after age 69 years. This is expected to result in reduced incidence and surgery rates for women aged 70-79. But the decline in incidence and breast surgery rates in women aged 70-79 was small and can only compensate for a fraction of the increase in incidence and breast surgery rates in women invited to screening. $^{78}$

In a recent review, preoperative magnetic resonance imaging was associated with more radical surgery. ${ }^{11}$ Increased access to modern breast reconstruction after mastectomy may have a similar effect. In Norway, however, the use of preoperative magnetic resonance imaging and breast reconstruction after mastectomy were limited during the study period. In the United States an increase in the proportion of breast cancer cases treated by mastectomy has been reported in recent years, ${ }^{12}$ mainly explained by changes in patients' attitudes and choices. Until 2008 this trend was not seen in data from Norway.

\section{Comparison with other studies}

Published data on how the introduction of mammography screening affects the type of surgery are limited. Similar trends in mastectomy rates were found in a study that compared surgery 
during 1994-9 in Northern Ireland (with screening) with that in the Republic of Ireland (without screening). ${ }^{13}$ Studies from Italy have shown declining mastectomy rates in the screening period, ${ }^{14}{ }^{15}$ but control groups have been missing. A study from the United Kingdom reported increased mastectomy rates for ductal carcinoma in situ within the screening programme but did not report data for invasive breast cancer. ${ }^{16}$ Recent data from Denmark show a large increase in mastectomies when screening first started that was not compensated for later on. ${ }^{17}$

\section{Conclusions}

Mammography screening is associated with a noticeable increase in breast surgery rates. In contrast with what has been claimed in invitations to screening and on websites supported by numerous governmental screening institutions and cancer charities, screening does not lead to a reduction in mastectomy rates. When screening was introduced in Norway, mastectomy rates increased. In recent years, as a result of changes to surgical policy, mastectomy rates have declined for all age groups, but mostly for the non-screened age groups.

Contributors: PS acquired and analysed the data and wrote the initial draft of the manuscript. JM designed the study. ES provided expert clinical advice. PHZ designed the study and led the statistical analysis. All authors interpreted the data, contributed and commented on drafts of the article, and approved the final version. JM and $\mathrm{PHZ}$ are guarantors.

Funding: PS is supported by the South-Eastern Norway Regional Health Authority.

Competing interests: All authors have completed the ICMJE uniform disclosure form at www.icmje.org/coi_disclosure.pdf (available on request from the corresponding author) and declare: no support from any organisation for the submitted work; no financial relationships with any organisations that might have an interest in the submitted work in the previous three years; no other relationships or activities that could appear to have influenced the submitted work.

Ethical approval: Not required.
Data sharing: No additional data available.

1 Jørgensen KJ, Gøtzsche PC. Presentation on websites of possible benefits and harms from screening for breast cancer: cross sectional study. BMJ 2004;328:148-51.

2 Jørgensen KJ, Gøtzsche PC. Content of invitations for publicly funded screening mammography. BMJ 2006;332:538-41.

3 De Koning HJ, van Dongen JA, van der Maas PJ. Changes in use of breast-conserving therapy in years 1978-2000. Br J Cancer 1994;70:1165-70.

4 Gøtzsche PC, Nielsen M. Screening for breast cancer with mammography. Cochrane Database Syst Rev 2009;CD001877.

5 Hofvind S, Geller B, Vacek PM, Thoresen S, Skaane P. Using the European guidelines to evaluate the Norwegian Breast Cancer Screening Program. Eur J Epidemiol 2007;22:447-55

6 Schlichting E, Harr ME, Sauer T, Babovic A, Kåresen R. [Sentinel lymph node biopsy in breast cancer]. Tidsskr Nor Laegeforen 2006;126:2098-100.

7 Zahl PH, Strand BH, Mæhlen J. Incidence of breast cancer in Norway and Sweden during introduction of nationwide screening: prospective cohort study. BMJ 2004;328:921-4.

8 Jørgensen KJ, Gøtzsche PC. Overdiagnosis in publicly organised mammography screening programmes: systematic review of incidence trends. BMJ 2009;339:b2587.

9 Bray F, ed in chief. Cancer in Norway 2006. Cancer incidence, mortality, survival and prevalence in Norway. Cancer Registry of Norway; 2007.

10 Hiotis K, Ye W, Sposto R, Skinner KA. Predictors of breast conservation therapy: size is not all that matters. Cancer 2005;103:892-9.

11 Houssami N, Hayes DF. Review of preoperative magnetic resonance imaging (MRI) in breast cancer: should MRI be performed on all women with newly diagnosed, early stage breast cancer? CA Cancer J Clin 2009;59:290-302.

12 McGuire KP, Santillan AA, Kaur P, Meade T, Parbhoo J, Mathias M, et al. Are mastectomies on the rise? A 13-year trend analysis of the selection of mastectomy versus breast conservation therapy in 5865 patients. Ann Surg Oncol 2009;16:2682-90.

13 Walsh PM, McCarron P, Middleton RJ, Comber H, Gavin AT, Murray L. Influence of mammographic screening on trends in breast-conserving surgery in Ireland. Eur J Cancer Prev 2006;15:138-48.

14 Paci E, Duffy SW, Giorgi D, Zappa M, Crocetti E, Vezzosi V, et al. Are breast cancer screening programmes increasing rates of mastectomy? Observational study. BMJ 2002;325:418.

15 Zorzi M, Puliti D, Vettorazzi M, De L, V, Falcini F, Federico M, et al. Mastectomy rates are decreasing in the era of service screening: a population-based study in Italy (1997-2001). Br J Cancer 2006:95:1265-8.

16 Dixon JM. Breast screening has increased the number of mastectomies. Breast Cancer Res 2009;11(suppl 3):S19.

17 Jørgensen KJ, Keen JD, Gøtzsche PC. Is mammographic screening justifiable considering its substantial overdiagnosis rate and minor effect on mortality? Radiology 2011;260:621-7.

Accepted: 7 July 2011

\section{Cite this as: BMJ 2011;343:d4692}

This is an open-access article distributed under the terms of the Creative Commons Attribution Non-commercial License, which permits use, distribution, and reproduction in any medium, provided the original work is properly cited, the use is non commercial and is otherwise in compliance with the license. See: http://creativecommons.org/licenses/bync/2.0/ and http://creativecommons.org/licenses/by-nc/2.0/legalcode. 


\section{What is already known on this topic}

Mammography screening increases overall rates of breast surgery

Women invited to mammography screening are informed that participation reduces their risk of having a mastectomy

\section{What this study adds}

Mammography screening is associated with an increase in mastectomy rates, especially when screening is in its introduction phase

Women should be informed that higher overall breast surgery rates in those invited to mammography screening partly results from higher mastectomy rates

\section{Tables}

Table 1| Number of cases and surgical treatment of invasive breast cancer and ductal carcinoma in situ in Norwegian women aged 40-79, 1993 to 2008

\begin{tabular}{|c|c|c|c|c|c|c|c|c|c|}
\hline \multirow[b]{2}{*}{ Year } & \multirow[b]{2}{*}{$\begin{array}{c}\text { Invasive } \\
\text { breast } \\
\text { cancer }\end{array}$} & \multirow[b]{2}{*}{$\begin{array}{l}\text { Ductal } \\
\text { carcinoma } \\
\text { in situ }\end{array}$} & \multicolumn{2}{|c|}{$\begin{array}{l}\text { Treatment for invasive breast } \\
\text { cancer }\end{array}$} & \multicolumn{2}{|c|}{$\begin{array}{l}\text { Treatment for ductal carcinoma } \\
\text { in situ }\end{array}$} & \multicolumn{2}{|c|}{ Missing information } & \multirow[b]{2}{*}{$\begin{array}{c}\text { Population of } \\
\text { women aged } \\
40-79\end{array}$} \\
\hline & & & Mastectomy & $\begin{array}{c}\text { Breast } \\
\text { conserving } \\
\text { therapy }\end{array}$ & Mastectomy & $\begin{array}{l}\text { Breast } \\
\text { conserving } \\
\text { therapy }\end{array}$ & $\begin{array}{c}\text { Invasive } \\
\text { breast cancer }\end{array}$ & $\begin{array}{l}\text { Ductal } \\
\text { carcinoma } \\
\text { in situ }\end{array}$ & \\
\hline 1993 & 1521 & 76 & 1228 & 171 & 53 & 23 & 122 & 0 & 882064 \\
\hline 1994 & 1581 & 86 & 1307 & 174 & 66 & 20 & 100 & 0 & 889565 \\
\hline 1995 & 1646 & 87 & 1322 & 197 & 55 & 32 & 127 & 0 & 897142 \\
\hline 1996 & 1891 & 161 & 1498 & 280 & 100 & 61 & 113 & 0 & 904611 \\
\hline 1997 & 1956 & 203 & 1525 & 328 & 118 & 82 & 103 & 3 & 912580 \\
\hline 1998 & 1943 & 197 & 1331 & 488 & 114 & 83 & 124 & 0 & 919467 \\
\hline 1999 & 1945 & 161 & 1318 & 511 & 90 & 70 & 116 & 1 & 927020 \\
\hline 2000 & 2037 & 205 & 1278 & 650 & 112 & 91 & 109 & 2 & 936320 \\
\hline 2001 & 2151 & 209 & 1286 & 782 & 106 & 101 & 83 & 2 & 941338 \\
\hline 2002 & 2186 & 243 & 1167 & 937 & 116 & 124 & 82 & 3 & 947989 \\
\hline 2003 & 2231 & 237 & 945 & 1198 & 82 & 150 & 88 & 5 & 955825 \\
\hline 2004 & 2241 & 282 & 899 & 1244 & 86 & 195 & 98 & 1 & 964939 \\
\hline 2005 & 2241 & 271 & 847 & 1284 & 80 & 188 & 110 & 3 & 976041 \\
\hline 2006 & 2173 & 249 & 875 & 1200 & 76 & 166 & 98 & 7 & 988656 \\
\hline 2007 & 2196 & 273 & 933 & 1155 & 83 & 176 & 108 & 14 & 1002024 \\
\hline 2008 & 2261 & 268 & 906 & 1147 & 104 & 150 & 208 & 14 & 1017298 \\
\hline
\end{tabular}


Table 2| Rates of breast surgery and mastectomies and changes in rates of both invasive breast cancer and ductal carcinoma in situ for women aged 40-49, 50-69, and 70-79 in Norway in relation to screening periods

\begin{tabular}{|c|c|c|c|c|c|}
\hline \multirow[t]{2}{*}{ Outcome by age group } & \multicolumn{3}{|c|}{ Rate per 100000 women per year } & \multicolumn{2}{|c|}{ Hazard ratio $(95 \% \mathrm{Cl})$} \\
\hline & Pre-screening (1993-5) & $\begin{array}{c}\text { Introduction of screening } \\
(1996-2004)\end{array}$ & Screening (2005-8) & $1996-2004$ v 1993-5 & $2005-8 v 1993-5$ \\
\hline \multicolumn{6}{|l|}{ Breast surgery: } \\
\hline $40-49$ & 132.5 & 140.7 & 144.1 & 1.07 (1.00 to 1.14$)$ & $1.08(1.00$ to 1.16$)$ \\
\hline $50-69^{*}$ & 179.7 & 298.1 & 305.1 & $1.67(1.60$ to 1.75$)$ & $1.70(1.62$ to 1.78$)$ \\
\hline $70-79$ & 226.9 & 225.4 & 213.6 & 0.99 (0.93 to 1.06$)$ & $0.92(0.86$ to 1.00$)$ \\
\hline \multicolumn{6}{|l|}{ Mastectomy: } \\
\hline $40-49$ & 109.5 & 90.9 & 71.4 & 0.83 (0.78 to 0.90$)$ & 0.65 (0.59 to 0.71$)$ \\
\hline $50-69^{*}$ & 155.7 & 166.9 & 106.3 & 1.09 (1.03 to 1.14$)$ & $0.70(0.66$ to 0.75$)$ \\
\hline $70-79$ & 205.6 & 180.9 & 122.2 & 0.87 (0.82 to 0.94$)$ & 0.59 (0.54 to 0.64$)$ \\
\hline
\end{tabular}

*Invited age group in screening programme. 


\section{Figures}
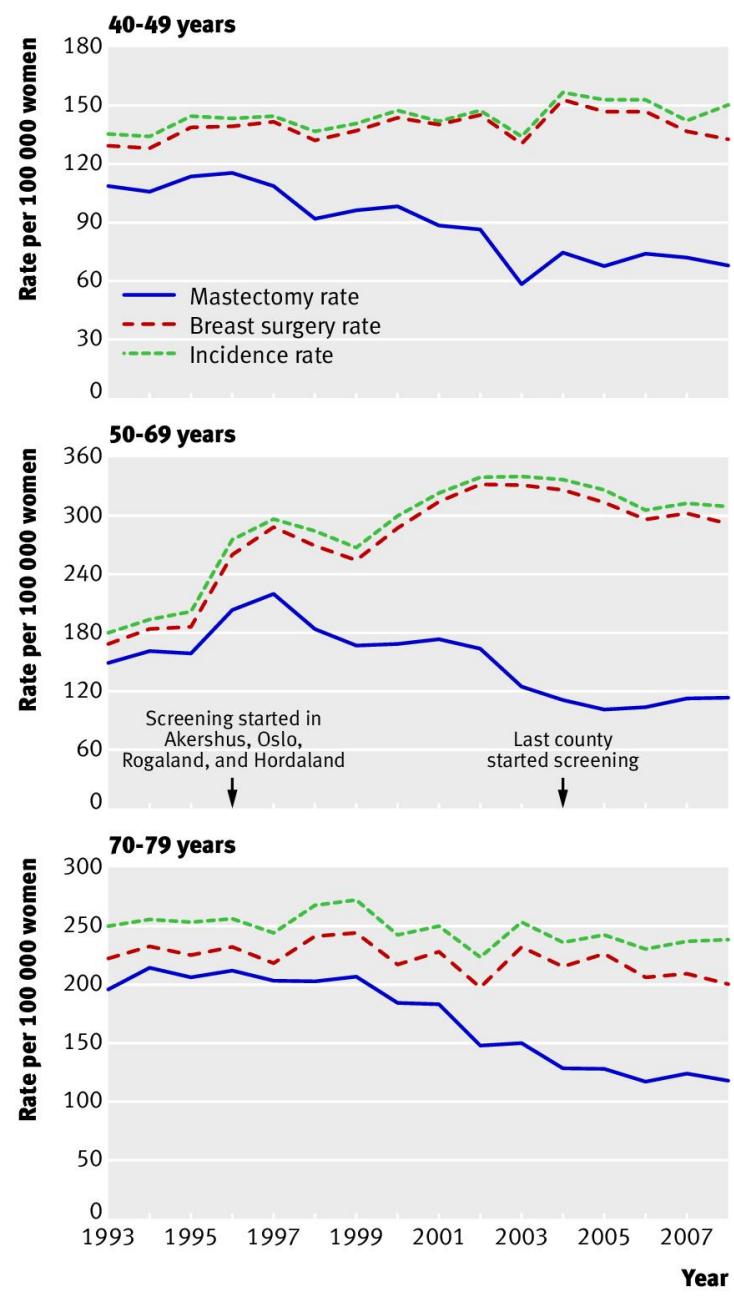

Fig 1 Age specific mastectomy, breast surgery (mastectomy plus breast conserving treatment), and incidence rates in Norwegian women with invasive breast cancer or ductal carcinoma in situ according to age group (women aged 50-69 are invited to screening)

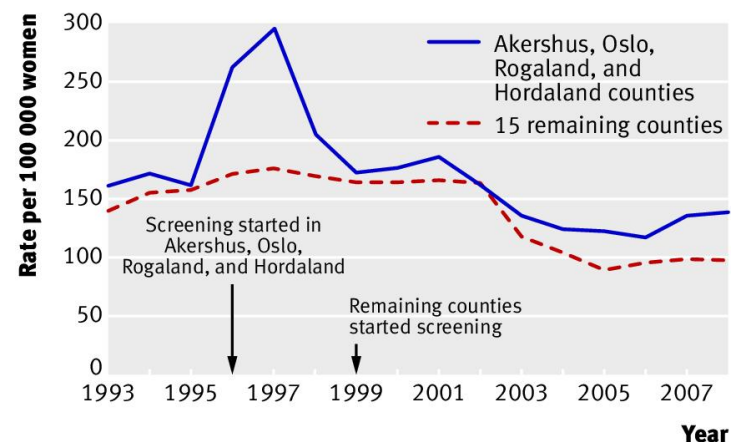

Fig 2 Mastectomy rates in Norwegian women aged 50-69 (age group invited to screening) with invasive breast cancer or ductal carcinoma in situ in Akershus, Oslo, Rogaland, and Hordaland counties (screening started in 1996) and remaining 15 counties (screening started 1999-2004) 

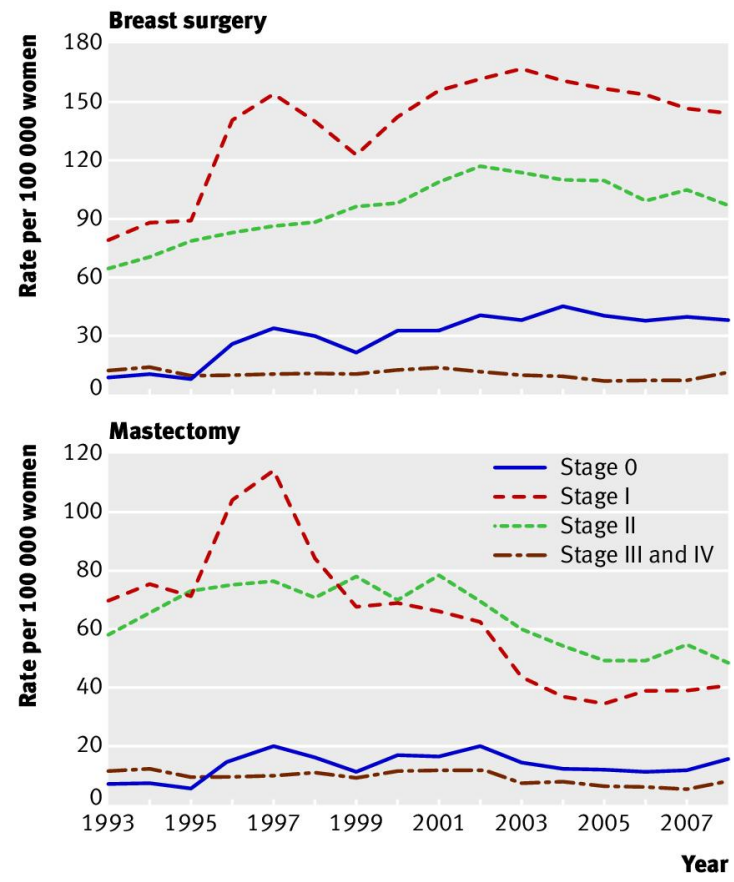

Fig 3 Age specific rates of breast surgery (mastectomy plus breast conserving treatment) and mastectomy in Norwegian women aged 50-69 (age group invited to screening) stratified by stage 